\title{
Glucagon-Expressing Neurons within the Retina Regulate the Proliferation of Neural Progenitors in the Circumferential Marginal Zone of the Avian Eye
}

\author{
Andy J. Fischer, ${ }^{1}$ Ghezal Omar, ${ }^{1}$ Nathaniel A. Walton, ${ }^{2}$ Thomas A. Verrill, ${ }^{1}$ and Cecilia G. Unson ${ }^{3}$ \\ ${ }^{1}$ Department of Neuroscience and ${ }^{2}$ The Graduate Program in Molecular, Cellular and Developmental Biology, The Ohio State University, Columbus, Ohio \\ 43210-1239, and ${ }^{3}$ Laboratory of Molecular Biology and Biochemistry, The Rockefeller University, New York, New York 10021
}

\begin{abstract}
Glucagon-expressing retinal amacrine cells have been implicated in regulating postnatal ocular growth. Furthermore, experimentally accelerated rates of ocular growth increase the number of neurons added to the peripheral edge of the retina. Accordingly, we assayed whether glucagon-expressing neurons within the retina regulate the proliferation of progenitors in the circumferential marginal zone (CMZ) of the postnatal chicken eye. We found that glucagon-containing neurites are heavily clustered within the CMZ at the peripheral edge of the retina. Many of these neurites originate from a cell type that is distinct from other types of retinal neurons, which we termed large glucagon-expressing neurons (LGENs). The LGENs are immunoreactive for glucagon and glucagon-like peptide 1 (GLP1), have a unipolar morphology, produce an axon that projects into the $\mathrm{CMZ}$, and are found only in ventral regions of the retina. In dorsal regions of the retina, a smaller version of the LGENs densely ramifies neurites in the CMZ. Intraocular injections of glucagon or GLP1 suppressed the proliferation of progenitors in the $\mathrm{CMZ}$, whereas a glucagon-receptor antagonist promoted proliferation. In addition, we found that glucagon, GLP1, and glucagon antagonist influenced the number of progenitors in the CMZ. We conclude that the LGENs may convey visual information to the CMZ to control the addition of new cells to the edge of the retina. We propose that glucagon/GLP1 released from LGENs acts in opposition to insulin (or insulin-like growth factor) to regulate precisely the proliferation of retinal progenitors in the CMZ.
\end{abstract}

Key words: retina; glucagon; proliferation; progenitor; stem cell; insulin

\section{Introduction}

The identification of neural stem cells in the eyes of warmblooded vertebrates has fueled optimism over the possibility of retinal regeneration in humans. Retinal stem cells in warmblooded vertebrates have been characterized from in vitro preparations of pigmented cells of the adult rodent and human ciliary body (Ahmad et al., 2000; Tropepe et al., 2000; Coles et al., 2004) and in vivo at the retinal margin (Fischer and Reh, 2000; Fischer et al., 2002b) and in the nonpigmented epithelium (NPE) of the ciliary body of the postnatal chicken (Fischer and Reh, 2003). In the chicken, we have identified a zone of neural progenitors that persists into adulthood and continues to add neurons to the peripheral edge of the retina as the globe of the eye expands during postnatal development (Fischer and Reh, 2000; Fischer et al.,

Received Aug. 3, 2005; revised Sept. 19, 2005; accepted Sept. 23, 2005.

This work was supported by start-up funds provided by The Ohio State University and National Science Foundation Grant 0413795. We thank David Schoenberg and Drs. W. K. Stell, R. Burry, and G. Bishop for comments that contributed to the final form of this manuscript. We thank Drs. Paul Henion and Virginia Lee for providing antibodies to transitin and neurofilament, respectively. The Pax6 and BrdU antibodies developed by Drs. A. Kawakami and S. J. Kaufman, respectively, were obtained from the Developmental Studies Hybridoma Bank developed under auspices of the National Institute of Child Health and Human Development and maintained by the University of lowa, Department of Biological Sciences (lowa City, IA).

Correspondence should be addressed to Andy J. Fischer, Department of Neuroscience, The Ohio State University College of Medicine and Public Health, 3020 Graves Hall, 333 West 10th Avenue, Columbus, OH 43210-1239. E-mail: fischer.412@0su.edu.

DOI:10.1523/JNEUROSCI.3247-05.2005

Copyright $\odot 2005$ Society for Neuroscience $\quad$ 0270-6474/05/2510157-10\$15.00/0 2002b; Fischer, 2005). The progenitors at the retinal margin can be stimulated to proliferate and add neurons to the edge of the retina by insulin-like growth factor I (IGF-I), epidermal growth factor (EGF), insulin, or Sonic Hedgehog (Shh) (Fischer and Reh, 2000; Fischer et al., 2002a; Moshiri et al., 2005). The zone of progenitors at the retinal margin of the postnatal chicken is similar to the well described circumferential marginal zone (CMZ) of fish and frogs (Raymond and Hitchcock, 1997, 2000; Reh and Fischer, 2001; Hitchcock et al., 2004). The purpose of this study was to assess whether glucagon influences the proliferation of cells within the CMZ of the postnatal chicken.

Glucagon is a 29 amino acid peptide that is highly conserved across species and belongs to the VIP-secretin-glucagon family of peptides. Glucagon and related peptides are derived from proglucagon mRNA and propeptide by tissue-specific processing of the full-length precursor peptide (mammals) or alternative splicing of the mRNA (in birds and fish) (Irwin and Wong, 1995). Proglucagon can give rise to five secreted bioactive peptides, glucagon, mini-glucagon, oxyntomodulin, and glucagon-like peptides 1 and 2 (GLP1 and GLP2). To date, there is no evidence for or against the production of GLP1/2 in the vertebrate retina. In contrast, glucagon has been reported to be expressed by a class of neurons comprising 1-2\% of the amacrine cells in the chicken retina (Tornqvist et al., 1981; Kuwayama et al., 1982; Tornqvist and Ehinger, 1983; Ekman and Tornqvist, 1985). Furthermore, there are reports of additional types of large glucagon- 
immunoreactive neurons in the pigeon retina (Karten and Brecha, 1983) and a "dense fiber plexus" immunoreactive for glucagon in the periphery of the chick retina (Kiyama et al., 1985). Despite the characterization of its distribution, the functions of glucagon in the retina remain poorly understood. Glucagoncontaining amacrine cells and glucagon peptide have been implicated as key players in vision-guided ocular growth and the development of myopia (Fischer et al., 1999b; Feldkaemper and Schaeffel, 2002). Interestingly, we found that increased rates of ocular growth stimulate the proliferation of progenitors in the avian CMZ (Fischer and Reh, 2000). Thus, we hypothesized that one function of retinal glucagon may be to regulate the proliferation of neural progenitors in the CMZ.

\section{Materials and Methods}

Animals. The use of animals in these experiments was in accordance with the guidelines established by the National Institutes of Health and The Ohio State University. For all experiments, we used hatched leghorn chickens (Gallus gallus domesticus) that were obtained from the Department of Animal Sciences at The Ohio State University. The chicks were used between postnatal day $1(\mathrm{P} 1)$ and P14. The chicks were kept on a $12 \mathrm{~h}$ light/dark cycle (lights on at 7:00 A.M.). Chicks were housed in a stainless-steel brooder at $\sim 30^{\circ} \mathrm{C}$ and received water and Purina (Purina Mills, St. Louis, MO) chick starter ad libitum.

Intraocular injections. Chicks were anesthetized and injected as described previously (Fischer et al., 1998, 1999a,b). For all experiments, the left eyes of chicks were injected with the "test" compound, and the contralateral eyes were injected with vehicle as a control. Growth factors were injected in $20 \mu \mathrm{l}$ of sterile saline with $0.1 \mathrm{mg} / \mathrm{ml}$ bovine serum albumin added as carrier. Growth factors used in these studies included human glucagon (500 ng per dose), porcine GLP1 (500 ng per dose), bovine insulin (500 ng per dose; Sigma, St. Louis, MO), and glucagon antagonist [des-His ${ }^{1}$, Glu ${ }^{9}$-glucagon- $\mathrm{NH}_{2}-\left(\mathrm{Phe}^{6}\right) ; 500-1000$ ng per dose]. Two micrograms of bromodeoxyuridine (BrdU) were included with each injection to label proliferating cells. All drugs and growth factors were obtained from Sigma.

Fixation and immunocytochemistry. Cells were fixed and immunolabeled as described previously (Fischer et al., 1998; Fischer and Stell, 1999). Working dilutions and sources of antibodies used in this study included the following: mouse anti-transitin at 1:600 (7B3A5; Dr. P. Henion, The Ohio State University); mouse anti-Pax6 at 1:50 (Pax6; Developmental Studies Hybridoma Bank, Iowa City, IA); mouse anti-BrdU at 1:50 (G3G4; Developmental Studies Hybridoma Bank); rat anti-BrdU at 1:200 (Accurate Chemicals, Westbury, NY); mouse antiglucagon at 1:400 (Dr. M. Gregor, University of Tübingen via Center for Ulcer Research and Education, University of California, Los Angeles, Los Angeles, CA); rabbit anti-GLP1 at 1:1000 (Novus Biologicals, Newington, NH); rabbit anti-glucagon receptor at 1:400 (ST-18; developed by Dr. C. Unson-O'Brien); and rabbit anti-cleaved caspase 3 at 1:800 (CPP32; R \& D Systems, Minneapolis, MN). Secondary antibodies included goat anti-rabbit Alexa 488, goat anti-mouse Alexa 488/568, and goat anti-mouse IgM Alexa 568 (Invitrogen, San Diego, CA) diluted to 1:1000 in PBS plus $0.2 \%$ Triton X-100. Some samples were counterstained with SyTox Orange (Invitrogen) to label nuclei, as per the manufacturer's recommended protocols.

Retrograde labeling. To label the neurites in the CMZ, we applied NeuroTrace DiI paste (Invitrogen) to the peripheral edge of the retina. Tissues were fixed for $15 \mathrm{~min}$ in $4 \%$ paraformaldehyde plus 3\% sucrose in $0.1 \mathrm{~m}$ phosphate buffer, $\mathrm{pH} 7.4$, and washed three times in PBS. The dense gel vitreous that adheres to the ciliary body and peripheral edge of the retina cannot be removed without destroying the peripheral retina and prevents access to the CMZ. Accordingly, the DiI paste (between 1 and 3 $\mu$ l) was applied, under $20 \times$ magnification using a stereo microscope and fine forceps, to the CMZ along the cut edge of the pie-shaped wedges of the anterior hemisphere of the eye. Samples were stored in PBS at $4^{\circ} \mathrm{C}$ for 4 weeks before mounting under coverslips for observation.

Terminal deoxynucleotidyl transferase-mediated biotinylated UTP nick end labeling assay. Fragmented DNA was detected in tissue sections by using the terminal deoxynucleotidyl transferase-mediated biotinylated UTP nick end labeling (TUNEL) method and the In Situ Cell Death Detection kit (TMR red; Roche Diagnostics, Indianapolis, IN), as per the manufacturer's protocols.

Reverse transcriptase-PCR. Retinas from three animals were pooled and placed in $1.5 \mathrm{ml}$ of Trizol reagent (Invitrogen), and total RNA was isolated according to the Trizol protocol and resuspended in $50 \mu \mathrm{l}$ of RNase-free water. Genomic DNA was removed by using the DNA Free kit provided by Ambion (Austin, TX). cDNA was synthesized from mRNA by using Superscript II First Strand Synthesis system (Invitrogen) and oligo-dT primers according to the manufacturer's protocol. Control reactions were performed using all components with the exception of the reverse transcriptase (RT) to exclude the possibility that primers were amplifying genomic DNA.

PCR primers were designed by using the web-based program Primer 3 from the Whitehead Institute for Biomedical Research (http://www. genome.wi.mit.edu/cgi-bin/primer/primer3_www.cgi). Primer sequences are as follows: glucagon propeptide (GPP) forward, 5'CACAGACTTGGAATGGTGA-3', GPP reverse, 5'-AAGGTCAAGCTGCCAAAGAA-3'; glucagon receptor forward, 5' -ACATCCACATGAACCTCTTCG-3', glucagon receptor reverse, 5' -TAGTCCGTGTAGCGCATCTG-3'; and GLP1 receptor forward, 5'-AAGAATGCCTGTGGTGACAGT-3', GLP1 receptor reverse, 5'-TGCCTCCACTACTGATGCTG-3'. Predicted product sizes (in base pairs) were 899 (GPP), 620 (glucagon receptor), and 529 (GLP1 receptor). PCR was performed by using standard protocols and an Eppendorf Scientific (Westbury, NY) thermal cycler. PCR products were run on an agarose gel to verify the predicted product sizes.

Photography, measurements, cell counts, and statistical analyses. Photomicrographs were taken by using a Leica (Nussloch, Germany) DM5000B microscope equipped with epifluorescence and a 12 megapixel Leica DC500 digital camera. Confocal microscopy was performed by using a Zeiss LSM 510 Meta. Images were optimized for color, brightness, and contrast, and double-labeled images were overlaid by using Adobe Photoshop 6.0 (Adobe Systems, San Jose, CA). Blind to the treatments, cell counts were made from at least five retinal sections or whole mounts from five different animals, and experiments were repeated at least once. Means and SEs were calculated on data sets from at least five individuals. To avoid the possibility of region-specific differences within the retina, cell counts were made consistently from the same region of the retina for each data set. Data from treated and control eyes were compared statistically with the appropriate Student's $t$ test. To determine whether cells were distributed in a regularly patterned array, we calculated an index of regularity as the mean distance to the nearest neighbor divided by the SD (Wassle and Riemann, 1978). The higher this ratio, the more regular the pattern of distribution; $>7$ represents a highly regular distribution, whereas values $<3$ represent a nonregular distribution. The distance between 40 different cells was measured from the center of one cell to the center of the next nearest cell in whole-mount preparations of the retina.

\section{Results}

\section{Glucagon-immunoreactive neurites are densely clustered at} the peripheral edge of the retina within the $\mathrm{CMZ}$

All of the experiments in this study were performed using postnatal chickens between 1 and $14 \mathrm{~d}$ of age. To localize glucagon in the retina, we used a monoclonal antibody to glucagon that does not discriminate between proglucagon and mature glucagon and does not cross react with GLP1 or GLP2 (Gregor and Riecken, 1985). In addition to the well described glucagon-expressing amacrine cells in the avian retina (Fig. 1a) (Kuwayama et al., 1982; Ekman and Tornqvist, 1985; Fischer et al., 1999a), we found that glucagon-immunoreactive neurites are densely clustered at the retinal margin (Fig. 1b), where retinal progenitors are known to reside (Fischer and Reh, 2000; Fischer et al., 2002a). The distribution of numerous glucagon-immunoreactive neurites in the peripheral retina is consistent with previous findings of a dense 


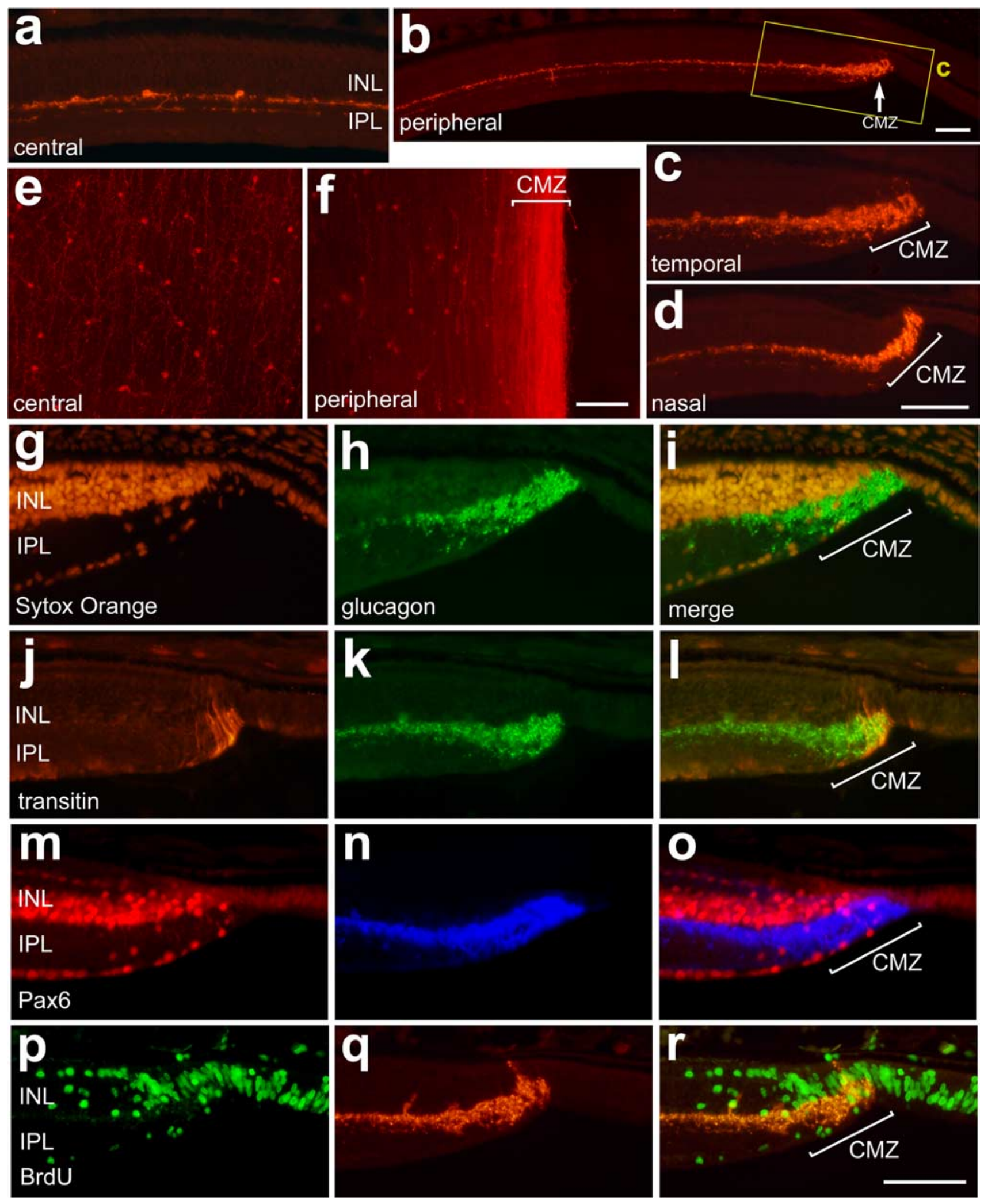

Figure 1. The neurites of glucagon-expressing neurons are heavily clustered in the circumferential marginal zone of retinal progenitors. Vertical retinal sections $(\boldsymbol{a}, \boldsymbol{b}, \boldsymbol{c}-\boldsymbol{r})$ and flat mounts $(\boldsymbol{e}, \boldsymbol{f})$ were labeled with antibodies to glucagon $(\boldsymbol{a}-\boldsymbol{d}, \boldsymbol{h}, \boldsymbol{k}, \boldsymbol{n}, \boldsymbol{q})$ and Sytox Orange $(\boldsymbol{g})$ or antibodies to transitin (j), Pax6 ( $\boldsymbol{m})$, or BrdU $(\boldsymbol{p})$. The retina in $\boldsymbol{p}-\boldsymbol{r}$ was obtained from an eye that received two consecutive daily intraocular injections of $1 \mu \mathrm{g}$ of insulin and $2 \mu \mathrm{g}$ of BrdU. Scale bars: $\boldsymbol{b}$ (for $\boldsymbol{a}, \boldsymbol{b}), \boldsymbol{d}, \boldsymbol{f}($ for $\boldsymbol{c}-\boldsymbol{f}), \boldsymbol{r}($ for $\boldsymbol{g}-\boldsymbol{r}), 50 \mu \mathrm{m}$.

fiber plexus in the periphery of the chick retina (Kiyama et al., 1985). Compared with central regions of the retina that contain sparsely distributed glucagon-containing dendrites in narrow strata in the distal inner plexiform layer (IPL) (Fig. 1a), the den- sity of glucagon-immunoreactive neurites is increased greatly in both nasal and temporal regions of the CMZ (Fig. 1b-d). The clustering of glucagon-immunoreactive neurites was evident in retinal sections and flat-mount preparations (Fig. 1e,f). We did 
not observe cell bodies that were immunoreactive for glucagon among the "nest" of neurites at the retinal margin (Fig. $1 g-i$ ). The glucagon-positive neurites appeared to fill out the peripheral edge of the IPL, which contained few nuclei (Figs. $1 g-i$ ). The glucagon-containing neurites extended into the CMZ and ramified among retinal progenitors that expressed transitin (the avian homolog of mammalian nestin) (Fig. $1 j-l$ ) and Pax6 (Fig. $1 m-o$ ). The glucagon-containing neurites did not extend beyond the CMZ into the NPE of the ciliary body that expresses Pax6 (Fig. $1 \mathrm{~m}-$ $o$ ), a tissue that is known to contain cells with neurogenic potential (Fischer and Reh, 2003).

We have reported previously that insulin and IGF-I stimulate the proliferation of progenitors in the $\mathrm{CMZ}$ and promote the addition of new cells into the peripheral edge of the retina (Fischer and Reh, 2000; Fischer et al., 2002b). To assay whether the distribution of glucagon-containing neurites was affected by the addition of new cells to the edge of the retina, we made two consecutive daily intraocular injections of insulin and BrdU (to label newly generated cells), harvested tissues $1 \mathrm{~d}$ after the final injection, and labeled sections with antibodies to glucagon and BrdU. We found that insulin-mediated addition of new cells to the edge of the retina did not displace the cluster of glucagon-containing neurites out of the CMZ and into the neural retina (Fig. $1 p-r$ ). This finding suggests that the glucagon-positive neurites in the CMZ may remodel with the addition of new cells to the peripheral edge of the retina to maintain their clustered distribution within the CMZ.

\section{Specificity of glucagon and GLP1 antibodies}

It is possible that, in addition to the production of glucagon, GLP1 is produced by neurons in the avian retina. We found that the antibodies to GLP1 labeled all the glucagon-containing amacrine cells across all regions of the retina $(n=247)$ (Fig. $2 c)$. In ventral and mid-peripheral regions of the retina, we occasionally found large neurons with somata in the vitread inner nuclear layer (INL) that were immunoreactive for glucagon and GLP1 (Fig. 2d-f). All of these large glucagon-immunoreactive cells $(n=54)$ were also immunoreactive for GLP1. In addition, the neurites clustered within the CMZ were immunoreactive for both glucagon and GLP1 (Fig. $2 g-i$ ).

To assay the specificity of the glucagon and GLP1 antibodies, we performed preabsorption experiments. Immunolabeling with the anti-glucagon and anti-GLP1 was blocked by preabsorption with $10^{-5} \mathrm{M}$ glucagon or GLP1, respectively. Preabsorption of the anti-glucagon with $10^{-5} \mathrm{M}$ GLP1 did not prevent immunolabeling. In contrast, preabsorption of the anti-GLP1 with $10^{-5} \mathrm{M}$ glucagon blocked labeling of the glucagon-positive amacrine cells, whereas GLP1 immunoreactivity in the somata of large neurons in the INL and neurites in the CMZ was maintained (Fig. $2 j-n)$, suggesting that the neurites in the CMZ arise from the large neurons. These findings suggest that IgG species within the GLP1 polyclonal antiserum cross-react with glucagon, and GLP1specific, glucagon-insensitive IgG species may selectively label the large neurons.

\section{Identification of a unipolar neuron that projects to the $\mathrm{CMZ}$ of the retina}

To characterize better the large, sparsely distributed neurons that were immunoreactive for glucagon and GLP1, we made wholemount preparations of the retina. These cells were found only in ventral and mid-peripheral regions of the retina (Fig. $3 a, f)$. In postnatal retinas, there were only $\sim 240$ large glucagonimmunoreactive cells per retina $(242.2 \pm 83.0)$. The mean number of large glucagon-immunoreactive cells per retina did not vary significantly between animals of different ages [266.1 \pm 108.1 at $\mathrm{P} 1(n=5), 240.2 \pm 52.7$ at $\mathrm{P} 10(n=5)$, and $216 \pm 74.3$ at P14 $(n=4)]$. However, as suggested by the SD, there was a wide range in the number of large glucagon-immunoreactive cells detected per individual (between 143 and 408 cells per eye). There were approximately equal numbers of the large glucagonimmunoreactive cells in the temporal and nasal halves of the retina.

The somata of the large glucagon/GLP1-immunoreactive cells were $\sim 13 \mu \mathrm{m}$ in diameter $(13.4 \pm 1.0 \mu \mathrm{m} ; n=20)$. The size of these cells was similar to that of displaced ganglion cells and more 

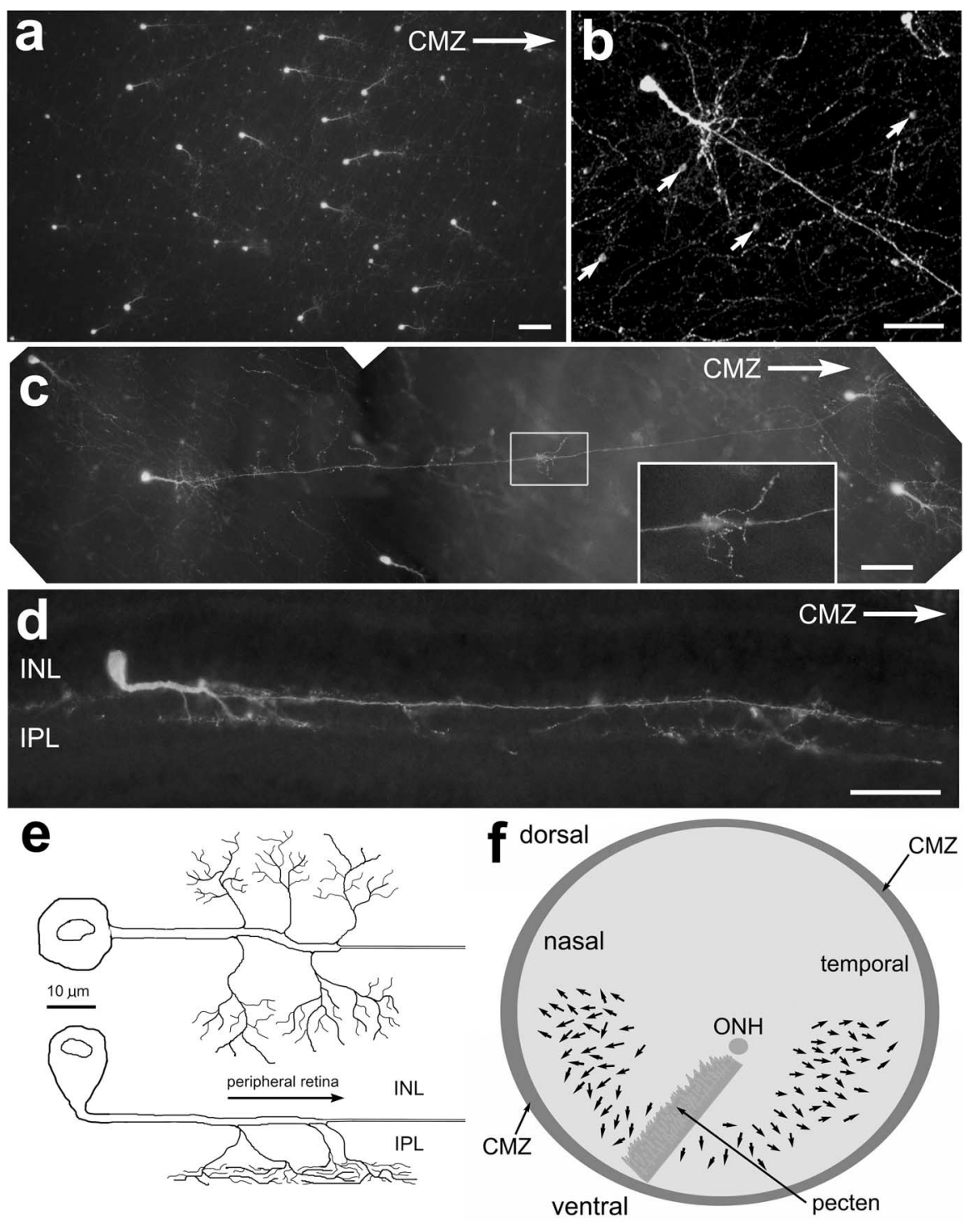

Figure 3. Unipolar neurons found in ventral, mid-peripheral regions of the retina produce axons that project toward the CMZ. Flat-mount preparations $(\boldsymbol{a}-\boldsymbol{c})$ and vertical retinal sections $(\boldsymbol{d})$ were labeled with antibodies to glucagon. We termed these cells LGENs. The inset in $c$ is a threefold-expanded field that demonstrates presumptive collateral arbor arising from the axon of an LGEN. Images were obtained by using standard epifluorescence microscopy $(\boldsymbol{a}, \boldsymbol{c}, \boldsymbol{d})$ or confocal microscopy $(\boldsymbol{b})$. The arrows in $\boldsymbol{b}$ indicate conventional glucagon-immunoreactive amacrine cells. Scale bar: $\boldsymbol{a}-\boldsymbol{d}, 50 \mu \mathrm{m}$. e schematically illustrates a typical LGEN as viewed in a flat-mount preparation (top) or vertical retinal section (bottom). $f$ is a schematic illustration of the distribution of LGENs and their projection (represented by arrows) in the retina. ONH, Optic nerve head.

than twice the diameter of the smaller glucagon-positive amacrine cells. The large glucagon/GLP1-immunoreactive cells had a unipolar morphology, producing a straight, thick primary neurite (up to $70 \mu \mathrm{m}$ in length) that produced many local dendritelike processes and an axon-like structure that formed at the peripheral tip of the thick primary neurite (Fig. $3 b, d, e$ ). Invariably, this axon-like process projected straight away from the soma toward the retinal margin (Fig. 3). We termed these cells large glucagon-expressing neurons (LGENs).

At low magnifications, the LGENs appeared to project in approximately the same direction, toward peripheral regions of the retina (Fig. $3 a$ ). However, the angles at which the LGENs projected toward the CMZ varied in different regions of the retina. In the most dorsal region where the LGENs are found, the projection of axons was angled toward the dorsal retina $\left(49.3 \pm 12.3^{\circ}\right.$ away from the CMZ in nasal retina and $33.2 \pm 16.4^{\circ}$ in temporal retina). By comparison, in more ventral regions of the retina, the directions of the axonal projections of the LGENs were angled more directly toward the $\mathrm{CMZ}$ $\left(20.3 \pm 29.6^{\circ}\right.$ in ventronasal retina and $-27.4 \pm 25.1^{\circ}$ in ventrotemporal retina). Although the LGENs were never found within $70 \mu \mathrm{m}$ of each other, the distribution pattern of these cells was quasiregular with a regularity index of 2.76 . The average distance between nearest neighboring LGENs was $129.0 \pm 56.8 \mu \mathrm{m}$.

To determine where the axonal projections of the LGENs terminate, we prepared retinal whole mounts that included the $\mathrm{CMZ}$ and digitally traced the course of the axon-like projections derived from individual LGENs by using high-resolution (12 megapixel) images and Adobe Photoshop 6.0. We found that every LGEN produced a single axon-like process that projected into the retinal margin (Fig. $4 a-c$, red, yellow, and light blue cells). In addition to the LGENs, we traced the projections of smaller $(9.0 \pm 0.6 \mu \mathrm{m}$ in diameter; $n=20)$ LGEN-like cells that were within $1.5 \mathrm{~mm}$ of the dorsal CMZ and followed their projections into the CMZ (Fig. $4 a, b$, dark blue and pink cells). These cells were distinctly larger than the conventional glucagon-containing amacrine cells (CGACs) but were smaller than LGENs (Fig. $4 d$ ). Although these cells had a variable morphology compared with that of the LGENs, these cells were unipolar, formed a short, crooked, thick primary neurite, and produced one to four neurites that projected up to $1.5 \mathrm{~mm}$ into the CMZ (Fig. $4 a-c$ ). Because of the similarities shared with LGENs, we termed these cells mini-LGENs. Unlike the LGENs, the mini-LGENs were scattered in the far peripheral regions of the dorsal retina.

We applied retrograde tracers to label the neurites that are clustered in the CMZ. We made injections of $40 \mathrm{~nm}$ fluorescent latex microspheres, lysinated fluorescein dextran, or diamidino yellow into the CMZ of intact eyes. However, delivery of these compounds into the CMZ inhibited axonal transport and failed to label the processes significantly (data not shown). Accordingly, we applied the lipophilic tracer DiI to the CMZ in paraformaldehyde-fixed samples. Although the DiI tracer failed to label neurites beyond $700 \mu \mathrm{m}$ from the site of application, the labeling did reveal that many varicose processes run parallel to the retinal margin within the CMZ (Fig. 4e,f). In addition, we found many DiI-labeled processes extending away from the CMZ toward central regions of the retina (Fig. 4e). This pattern of labeling was consistent in dorsal, ventral, nasal, and temporal quadrants of the CMZ. Because we failed to observe neurofilament or the neurites of dopaminergic amacrine cells within the CMZ, we assumed that the DiI-labeled processes in the CMZ were the glucagon/GLP1-immunoreactive processes. We propose that the glucagon/GLP1-positive neurites that are clus- 

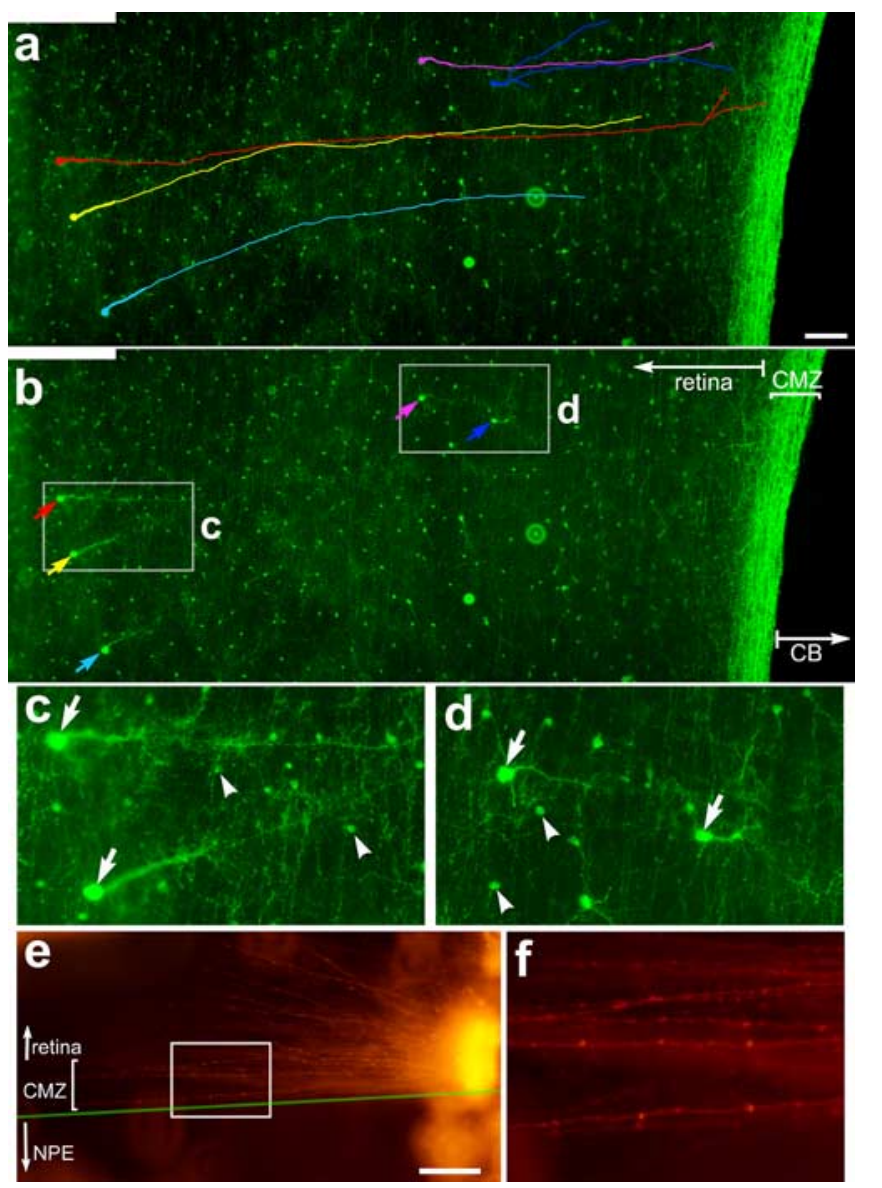

Figure 4. The axons of LGENs and mini-LGENs project toward the CMZ at the retinal margin Flat-mount preparations of the retina were labeled with antibodies to glucagon. The cell bodies, primary neurite, and axons of LGENs (orange, yellow, light blue) and mini-LGENs (pink and dark blue) were digitally traced by using Adobe Photoshop 6.0 in a montage of high-resolution images. $\boldsymbol{c}$ and $\boldsymbol{d}$ are threefold enlargements of the areas boxed in $\boldsymbol{b}$. $\boldsymbol{e}$ is a micrograph of flat-mounted peripheral retina, CMZ, and NPE where Dil (bright orange area) has been applied to the CMZ. In $\boldsymbol{e}$, the peripheral edge of the CMZ is indicated by the green line, and the boxed area is expanded threefold in $\boldsymbol{f}$ to demonstrate the varicose Dil-labeled processes that course within the CMZ. The colored arrows in $\boldsymbol{b}$ indicate the cell bodies of LGENs and mini-LGENs, the arrowheads in $\boldsymbol{c}$ and $\boldsymbol{d}$ indicate glucagon-positive amacrine cells, and the arrows in $\boldsymbol{c}$ and $\boldsymbol{d}$ indicate the cell bodies of LGENs and mini-LGENs, respectively. Scale bars: $\boldsymbol{a}$ (for $\boldsymbol{a}, \boldsymbol{b}), \boldsymbol{e}, 50 \mu \mathrm{m}$. CB, Ciliary body.

tered within the CMZ arise from LGENs in ventral regions of the retina and mini-LGENs in dorsal regions of the retina.

\section{The proliferation of progenitors in the $\mathrm{CMZ}$ is influenced by} intraocular injections of glucagon and related peptides

The neurites of glucagon/GLP1-expressing cells are heavily clustered within the zone of progenitors at the retinal margin, suggesting that the release of glucagon and/or GLP1 at the retinal margin may influence the neural progenitor cells in the CMZ. We have reported previously that insulin and IGF-I stimulate the proliferation of progenitors at the retinal margin and increase the number of cells that are added to the retina (Fischer and Reh, 2000; Fischer et al., 2002a). We used intraocular injections of BrdU to label proliferating cells, because this technique has been shown to only label proliferating cells that express proliferating cells nuclear antigen (PCNA) and phospho-histone $\mathrm{H} 3$ in the postnatal chicken retina (Fischer and Reh, 2000; Fischer et al., 2002a). We have reported previously that all BrdU-labeled cells within the CMZ are also immunoreactive for PCNA (Fischer and
Reh, 2000; Fischer et al., 2002a) and that intraocular injections, compared with subcutaneous applications of BrdU, do not induce ocular damage that stimulates the proliferation of progenitors in the CMZ or in the pars plana of the ciliary body (Fischer and Reh, 2003).

Because glucagon is best known to antagonize the physiological effects of insulin by increasing blood glucose levels, a parallel correlation is that glucagon at the retinal margin should act in opposition to insulin and suppress the proliferation of retinal progenitors. Indeed, we found that four consecutive daily intraocular injections of glucagon reduced the number of BrdUlabeled cells in nasal and temporal regions of the CMZ and NPE of the ciliary body (Fig. $5 a-e$ ). We found that GLP1, like glucagon, reduced the number of BrdU-labeled cells at the retinal margin and within the NPE, with significant effects occurring in temporal NPE but not nasal NPE (Fig. 5b). As reported previously (Fischer and Reh, 2000, 2003), intraocular injections of insulin increased the number of BrdU-labeled cells at the edge of the retina and within the NPE (Fig. $5 a-d$ ). Application of glucagon with insulin reduced the addition of newly generated cells to the edge of the retina and NPE compared with the number of cells seen with insulin alone (Fig. $5 a, b$ ). Four consecutive daily intraocular injections of $500 \mathrm{ng}$ glucagon antagonist did not affect the proliferation of cells in the CMZ or NPE (data not shown). By comparison, two consecutive intraocular injections of $1 \mu \mathrm{g}$ of glucagon antagonist increased the number of BrdU-labeled cells in the CMZ and NPE in temporal, but not nasal, regions of the eye (Fig. $5 f-h$ ). Together, our data suggest that glucagon/GLP1mediated control over the proliferation of neural progenitors in the $\mathrm{CMZ}$ is more pronounced in temporal than in nasal regions of the eye. The application of glucagon, GLP1, insulin, or glucagon antagonist did not compromise the survival of retinal cells; numbers of TUNEL-positive retinal cells and numbers of cells immunoreactive for activated caspase 3 were unaffected (data not shown).

\section{The number of transitin-expressing progenitors in the CMZ} is influenced by glucagon

We have reported previously that transitin, a nestin-related intermediate filament, is expressed by neural progenitors in the CMZ of the postnatal chick retina (Fischer and Omar, 2005). Therefore, we tested whether intraocular injections of insulin, glucagon, GLP1, or glucagon antagonist influenced the number of transitin-expressing retinal progenitors in the CMZ. We found that two consecutive daily intraocular injections of insulin significantly increased the number of transitin-positive cells in the CMZ compared with numbers of transitin-positive cells in the CMZ of saline-treated eyes (Fig. 6). In contrast, intraocular injections of glucagon or GLP1 decreased the number of transitinpositive progenitors in the CMZ (Fig. 6). Like insulin, the glucagon-antagonist increased the number of transitin-positive progenitors in the CMZ (Fig. 6a).

To test whether the reduction of transitin-positive cells in the CMZ that resulted from glucagon-treatment represents a permanent loss of progenitors, we assayed whether treatment with insulin after glucagon stimulated proliferation or the accumulation of transitin-positive cells within the CMZ. Using five animals, we made two consecutive daily intraocular injections of $500 \mathrm{ng}$ of glucagon into the left eye and saline into the right eye (contralateral control). This was followed by two consecutive daily injections of $500 \mathrm{ng}$ of insulin and $2 \mu \mathrm{g}$ of BrdU into both eyes. We found that pretreatment of eyes with glucagon moderately reduced the number of transitin-positive cells in the CMZ that 

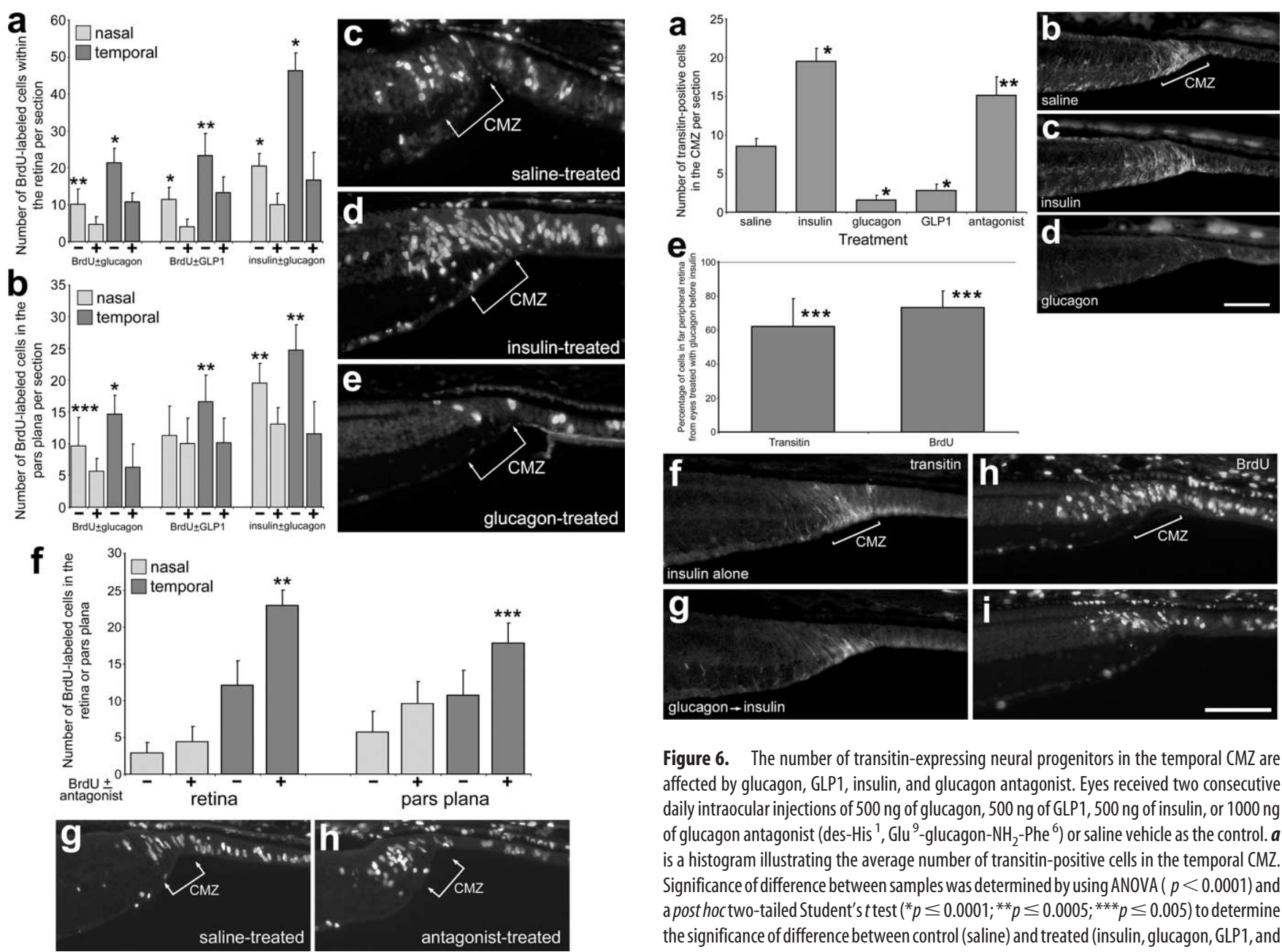

Figure 5. Intraocular injections of glucagon, GLP1, and glucagon antagonist regulate the proliferation of retinal progenitors in the $\mathrm{CMZ}$ and the addition of new cells to the peripheral edge of the retina. $\boldsymbol{a}-\boldsymbol{e}$, Eyes received four consecutive daily intraocular injections (from P1 through P4) of BrdU alone or with $500 \mathrm{ng}$ of glucagon, $500 \mathrm{ng}$ of GLP1, $500 \mathrm{ng}$ of insulin, or 500 ng of insulin and glucagon. Numbers of BrdU-labeled cells were counted in nasal and temporal regions of the CMZ and NPE of the pars plana (within $150 \mu \mathrm{m}$ of the neural retina). $\mathbf{c}-\boldsymbol{e}$ are representative micrographs of BrdU immunofluorescence at the peripheral edge of the retina from eyes treated with saline $(\boldsymbol{c})$, insulin $(\boldsymbol{d})$, or glucagon $(\boldsymbol{e}) . \boldsymbol{f}$ - $\boldsymbol{h}$, Eyes received two consecutive daily intraocular injections (from P2 through P5) of BrdU alone or with $1000 \mathrm{ng}$ of glucagon antagonist (des-His ${ }^{1}$, Glu ${ }^{9}$-glucagon- $\mathrm{NH}_{2}-\mathrm{Phe}^{6}$ ). $\boldsymbol{g}$ and $\boldsymbol{h}$ are representative micrographs of BrdU immunofluorescence at the peripheral edge of the retina from eyes treated with saline $(\boldsymbol{g})$ or glucagon antagonist (e). Significance of difference was determined by using an unpaired, two-tailed Student's $t$ test $\left({ }^{*} p \leq 0.0001 ;{ }^{* *} p \leq 0.002 ;{ }^{* * *} p \leq 0.05\right)$. Error bars represent the SD of the sample means.

would otherwise accumulate with saline pretreatment and insulin (Fig. $6 e-g$ ). Similarly, glucagon pretreatment reduced the number of BrdU-labeled cells added to the retinal margin compared to that which occurs with saline pretreatment before insulin (Fig. $6 e, h, i$ ). These findings suggest that glucagon treatment moderately reduces the potential of insulin to stimulate $\mathrm{CMZ}$ progenitors to express transitin and add cells to the edge of the retina.

\section{Receptors for glucagon and GLP1 are expressed within the retina and CMZ}

To test whether receptors for glucagon or GLP1 are expressed within the retina and CMZ, we used antibodies to the glucagon receptor and RT-PCR. We used polyclonal antibodies raised to the mouse glucagon receptor, which shares $>72 \%$ sequence

Figure 6. The number of transitin-expressing neural progenitors in the temporal CMZ are affected by glucagon, GLP1, insulin, and glucagon antagonist. Eyes received two consecutive daily intraocular injections of $500 \mathrm{ng}$ of glucagon, $500 \mathrm{ng}$ of GLP1, $500 \mathrm{ng}$ of insulin, or $1000 \mathrm{ng}$ of glucagon antagonist (des-His ${ }^{1}$, Glu ${ }^{9}$-glucagon- $\mathrm{NH}_{2}-\mathrm{Phe}^{6}$ ) or saline vehicle as the control. $\boldsymbol{a}$ is a histogram illustrating the average number of transitin-positive cells in the temporal CMZ. Significance of difference between samples was determined by using ANOVA ( $p<0.0001)$ and a post hoc two-tailed Student's t test $\left({ }^{*} p \leq 0.0001 ;{ }^{* *} p \leq 0.0005 ;{ }^{* * *} p \leq 0.005\right)$ to determine the significance of difference between control (saline) and treated (insulin, glucagon, GLP1, and antagonist) samples. Error bars represent the SD of sample means. $\boldsymbol{b}$ - $\boldsymbol{d}$ are fluorescent micrographs demonstrating transitin immunoreactivity in the far peripheral retina and CMZ of eyes injected with saline $(\boldsymbol{b})$, insulin $(\boldsymbol{c})$, or glucagon $(\boldsymbol{d})$. $\boldsymbol{e}-\boldsymbol{i}$, The left eyes received two consecutive daily intraocular injections of $500 \mathrm{ng}$ of glucagon, and the right eyes received saline, starting at P1. At P3, both eyes received two consecutive injections of $500 \mathrm{ng}$ of insulin and $2 \mu \mathrm{g}$ of BrdU, and eyes were harvested at P5. The histogram in $\mathbf{e}$ illustrates the percentage of transitin or BrdU-labeled cells within the far peripheral temporal retina. The percentage of cells was calculated as the total number of cells from three sections of retinas treated with glucagon followed by insulin, divided by the number of cells in retinas treated with saline followed by insulin from the same individual. The mean percentages were averaged for five individuals. Error bars represent the SD of sample means. $\boldsymbol{f}$ - $\boldsymbol{i}$ are fluorescent micrographs demonstrating transitin $(\boldsymbol{f}, \boldsymbol{g})$ or BrdU $(\boldsymbol{h}, \boldsymbol{i})$ immunoreactivity in the far peripheral retina and CMZ of eyes treated with salineinsulin $(\boldsymbol{f}, \boldsymbol{h})$ or glucagon-insulin $(\boldsymbol{g}, \boldsymbol{i})$. Scale bars: $\boldsymbol{d}$ (for $\boldsymbol{b}-\boldsymbol{d}), \boldsymbol{i}($ for $\boldsymbol{f}-\boldsymbol{i}), 50 \mu \mathrm{m}$.

identity and $>84 \%$ sequence homology with the chicken glucagon receptor (Feldkaemper et al., 2004). We found immunoreactivity for the glucagon receptor concentrated throughout the IPL, consistent with the distribution of neurites from glucagonexpressing amacrine cells (Fig. $7 a-c$ ). In addition, we found immunoreactivity for the glucagon receptors in the outer segments of photoreceptors, the outer plexiform layer (OPL), somata of amacrine cells, ganglion cells, and the nerve fiber layer (Fig. $7 a-$ $c)$. These findings are consistent with a previous report that used in situ hybridization to localize the mRNA for the glucagon receptor (Feldkaemper et al., 2004). At the retinal margin, immunoreactivity for the glucagon receptor was concentrated in the CMZ, where glucagon-immunoreactive neurites are densely clustered (Fig. $7 d-h$ ). In addition, immunoreactivity for the glucagon receptor was present in the OPL, somata of amacrine cells, and ganglion cells (Fig. $7 g, h$ ). Western blot analysis revealed a 
band at $\sim 45 \mathrm{kDa}$, the predicted molecular weight of the chick glucagon receptor, and a second band at $\sim 30 \mathrm{kDa}$, which may represent a cleavage product of the glucagon receptor or cross-reactivity with an epitope sharing homology with the glucagon receptor (Fig. 7i). To further confirm that the glucagon receptor is expressed in the retina, we used RT-PCR. We detected mRNA for the glucagon propeptide, glucagon receptor, and GLP1 receptor in central and peripheral regions of the retina (Fig. 7j).

\section{Discussion}

We report here that neurites immunoreactive for glucagon and GLP1 are heavily clustered within the zone of progenitors at the retinal margin. This finding suggests that the release of glucagon and/or GLP1 at the retinal margin may influence the proliferation and/or differentiation of progenitor cells in the CMZ. The distribution of glucagon-containing processes within the progenitor zone at the retinal margin is reminiscent of the distribution of glucagon-containing process in peripheral regions of the turtle retina (Wetzel and Eldred, 1997). However, it remains unknown whether the eyes of turtles contain a zone of progenitors at the retinal margin. There have been reports that there are glucagon-immunoreactive "fascicles" in the ora serrata of the pigeon retina (Karten and Brecha, 1983). It is possible that, like the chicken retina, the pigeon retina contains a CMZ, and the fascicles of glucagonimmunoreactive neurites are gathered within the CMZ. In the chicken retina, Kiyama et al. (1985) have described a dense fiber plexus in the peripheral margin of the retina that is immunoreactive for glucagon. Data provided here indicate that the dense fiber plexus described 20 years ago by Kiyama and colleagues is ramified among neural progenitors in the CMZ.

The distribution of neurites from LGENs and mini-LGENs cells may be unique among retinal neurons. For example, dopaminergic amacrine cells, with large dendritic fields similar to those of the glucagonergic cells, do not concentrate processes within the CMZ at the retinal margin (data not shown). In addition, neurites immunoreactive for neurofilament or calretinin are not concentrated within the CMZ of the postnatal chicks (Fischer and Reh, 2000; Fischer et al., 2002b). These findings suggest that the clustering of glucagon-containing neurites is not caused by a general cue for the accumulation of neuronal processes in the CMZ.

The glucagon/GLP1-immunoreactive neurites in the CMZ appear to arise from unipolar axon-forming neurons that we termed LGENs and mini-LGENs. The LGENs have not been described thoroughly by previous studies. The LGENs may have gone essentially unstudied because of their low abundance, unique compliment of markers, and restricted location within the retina. In the classical studies by Ramon y Cajal, no reference is made to cells that share morphological similarities with the LGENs. Although Ramon y Cajal (1972) elegantly described the efferent target cells of the avian retina, which share some similarities with the LGENs, these cell types are distinctly different based on their abundance and morphology (Uchiyama and Ito, 1993; Uchiyama et al., 1995, 2004; Fischer and Stell, 1999). There are brief descriptions in the literature of the LGEN-like cells in the chicken retina. Several studies $>20$ years ago briefly mention large $(10-15 \mu \mathrm{m})$ glucagon-immunoreactive cells in peripheral regions of the retina but fail to provide images or describe the morphological features of these cells (Kuwayama et al., 1982; Kiyama et al., 1985). Cell types similar to LGENs and miniLGENs have been described in the pigeon retina and are mentioned briefly in a review by Karten and Brecha (1983). In the pigeon retina, glucagon immunoreactivity was observed in large $(\sim 12 \mu \mathrm{m})$ neurons in the dorsal retina, which form two or three primary neurites, and in very large $(\sim 18 \mu \mathrm{m})$ neurons in the ventral retina, which form a thick primary neurite. Both of these cell types form lengthy processes that project into "fascicles within the ora serrata" (Karten and Brecha, 1983). Unfortunately, images of these cells are available only in difficult-to-find 
books that are not referenced by PubMed (Brecha, 1983; Brecha and Karten, 1983). Nevertheless, the cells described by Karten and Brecha in the pigeon retina are likely to be equivalent to the LGENs and mini-LGENs that we describe in the chick retina.

We found that the number and proliferation of progenitors in the CMZ can be suppressed by exogenous glucagon and GLP1 and stimulated by insulin and glucagon antagonist. There are scattered reports that VIP-secretin-glucagon-like peptides can influence the proliferation of neural progenitors. There has been a report that GLP2 influences the proliferation of astrocytes in culture (Velazquez et al., 2003). Similarly, pituitary adenylate cyclase activating peptide (PACAP), a member of the VIP-secretin-glucagon family of peptides, is known to suppress proliferation and antagonize the actions of Shh in the developing neural tube (Waschek et al., 2000; Nicot et al., 2002). Interestingly, Shh has been reported recently to stimulate the proliferation of CMZ progenitors in the chick retina (Moshiri et al., 2005). In addition, PACAP has been shown to influence the proliferation, survival, differentiation, and neurite outgrowth of a variety of neuronal cell lines and primary cultures (Waschek et al., 2000). These findings indicate that VIP-secretin-glucagon-like peptides can play a role in neural development and are consistent with our current findings that glucagon and GLP1 suppress the proliferation of retinal progenitors. Our findings indicated that glucagon and GLP1 can be added to the long list of secreted factors that influence neural progenitors.

We found that glucagon and GLP1 decreased the number of transitin-positive progenitors in the CMZ, whereas insulin and a glucagon antagonist increased the number of these cells. These findings suggest that glucagon and GLP1 may decrease the number of progenitors in the CMZ. Alternatively, these findings may indicate that glucagon and GLP1 suppress the expression of transitin without affecting numbers of progenitors in the CMZ. Another possibility is that glucagon/GLP1 stimulates retinal progenitors in the CMZ to undergo terminal differentiation. We found that the application of glucagon before insulin reduced the number of transitin-expressing progenitors in the CMZ and moderately reduced the addition of new cells to the edge of the retina that is otherwise induced by insulin alone (Fig. 6). This finding is consistent with the hypothesis that glucagon reduces the number of retinal progenitors in the $\mathrm{CMZ}$ and that the decrease in transitin expression may represent a loss of progenitors that can be reactivated by insulin. Together, our findings suggest that postnatal retinal neurogenesis is regulated in a "push-pull" manner by glucagon/GLP1 and insulin.

In addition to the CMZ of the postnatal chicken eye, the NPE of the ciliary body is capable of producing neurons in vivo. Proliferation and neurogenesis can be induced by insulin, EGF, and FGF2 in a sizeable area of NPE cells $\left(20 \mathrm{~mm}^{2}\right.$ per eye) (Fischer and Reh, 2003). The NPE normally does not contain any neurons and is anterior to and contiguous with the CMZ (Fischer and Reh, 2003). The retina and NPE of the ciliary body are derived from the ventral diencephalon during development, but the mechanisms that control the formation of the CMZ and the mechanisms that prevent the NPE from becoming neural retina remain unknown. It is possible that the build-up of glucagonpositive neurites contributes to the formation of the CMZ and the transition of neural retina into the pseudo-stratified columnar NPE. Additional studies are required to study this possibility.

The CGACs and glucagon peptide in the avian eye have been shown to participate in vision-guided ocular growth, which occurs during postnatal development (Fischer et al., 1999b; Bitzer and Schaeffel, 2002; Feldkaemper and Schaeffel, 2002; Feldkaem- per et al., 2004). We have reported previously that the glucagoncontaining amacrine cells in the chicken retina respond to lensimposed hyperopia (which stimulates ocular growth) by decreasing expression levels of the immediate-early gene early growth response gene 1 (Egr1), whereas levels of Egr1 are increased in response to lens-imposed myopia (Fischer et al., 1999b). Furthermore, levels of retinal glucagon are increased transiently by lens-imposed myopia and reduced transiently by lens-imposed hyperopia (Feldkaemper et al., 2000; Buck et al., 2004). Recent studies have indicated that glucagon and oxyntomodulin inhibit form-deprivation myopia, and glucagon antagonist prevents lens-induced hyperopia (Vessy et al., 2005a,b). However, the glucagon-expressing cells that ramify neurites within the CMZ are distinctly different from the CGACs that may participate in visually guided ocular growth. This does not exclude the possibility that LGENs and mini-LGENs respond to visual cues that regulate ocular growth and somehow contribute to the retinal mechanisms that influence the growth of the eye.

\section{Conclusions}

We conclude that glucagon/GLP1-containing neurites are heavily clustered within the progenitor zone at the peripheral edge of the avian retina. These neurites in the CMZ appear to arise from retinal neurons, which we have termed LGENs and mini-LGENs. The LGENs and mini-LGENs are relatively large, unipolar neurons that form axon-like processes and are found in peripheral and ventral or dorsal retinal regions, respectively. Similar to the physiological antagonism of glucagon and insulin in regulating blood glucose homeostasis, we found that glucagon/ GLP1 and insulin act antagonistically to regulate the proliferation of retinal progenitors in the CMZ. We propose that the LGENs receive visual cues and relay these cues to the $\mathrm{CMZ}$ to regulate the proliferation of progenitors and the addition of new cells to the edge of the retina.

\section{References}

Ahmad I, Tang L, Pham H (2000) Identification of neural progenitors in the adult mammalian eye. Biochem Biophys Res Commun 270:517-521.

Bitzer M, Schaeffel F (2002) Defocus-induced changes in ZENK expression in the chicken retina. Invest Ophthalmol Vis Sci 43:246-252.

Brecha N (1983) A review of retinal neurotransmitters: histochemical and biochemical studies. In: Neurochemical anatomy (Emson PC, ed). New York: Raven.

Brecha NC, Karten HJ (1983) Identification and localization of neuropeptides in the vertebrate retina. In: Brain peptides (Kreiger D, Brownstein M, Martin J, eds). New York: Wiley.

Buck C, Schaeffel F, Simon P, Feldkaemper M (2004) Effects of positive and negative lens treatment on retinal and choroidal glucagon and glucagon receptor mRNA levels in the chicken. Invest Ophthalmol Vis Sci 45:402-409.

Coles BL, Angenieux B, Inoue T, Del Rio-Tsonis K, Spence JR, McInnes RR, Arsenijevic Y, van der Kooy D (2004) Facile isolation and the characterization of human retinal stem cells. Proc Natl Acad Sci USA 101:15772-15777.

Ekman R, Tornqvist K (1985) Glucagon and VIP in the retina. Invest Ophthalmol Vis Sci 26:1405-1409.

Feldkaemper MP, Schaeffel F (2002) Evidence for a potential role of glucagon during eye growth regulation in chicks. Vis Neurosci 19:755-766.

Feldkaemper MP, Wang HY, Schaeffel F (2000) Changes in retinal and choroidal gene expression during development of refractive errors in chicks. Invest Ophthalmol Vis Sci 41:1623-1628.

Feldkaemper MP, Burkhardt E, Schaeffel F (2004) Localization and regulation of glucagon receptors in the chick eye and preproglucagon and glucagon receptor expression in the mouse eye. Exp Eye Res 79:321-329.

Fischer AJ (2005) Neural regeneration in the chick retina. Prog Retin Eye Res 24:161-182.

Fischer AJ, Omar G (2005) Transitin, a nestin-related intermediate fila- 
ment, is expressed by neural progenitors and can be induced in Muller glia in the chicken retina. J Comp Neurol 484:1-14.

Fischer AJ, Reh TA (2000) Identification of a proliferating marginal zone of retinal progenitors in postnatal chickens. Dev Biol 220:197-210.

Fischer AJ, Reh TA (2003) Growth factors induce neurogenesis in the ciliary body. Dev Biol 259:225-240.

Fischer AJ, Stell WK (1999) Nitric oxide synthase-containing cells in the retina, pigmented epithelium, choroid, and sclera of the chick eye. J Comp Neurol 405:1-14.

Fischer AJ, Seltner RL, Poon J, Stell WK (1998) Immunocytochemical characterization of quisqualic acid- and $N$-methyl-D-aspartate-induced excitotoxicity in the retina of chicks. J Comp Neurol 393:1-15.

Fischer AJ, Morgan IG, Stell WK (1999a) Colchicine causes excessive ocular growth and myopia in chicks. Vision Res 39:685-697.

Fischer AJ, McGuire JJ, Schaeffel F, Stell WK (1999b) Light- and focusdependent expression of the transcription factor ZENK in the chick retina. Nat Neurosci 2:706-712.

Fischer AJ, McGuire CR, Dierks BD, Reh TA (2002a) Insulin and fibroblast growth factor 2 activate a neurogenic program in Müller glia of the chicken retina. J Neurosci 22:9387-9398.

Fischer AJ, Dierks BD, Reh TA (2002b) Exogenous growth factors induce the production of ganglion cells at the retinal margin. Development 129:2283-2291.

Gregor M, Riecken EO (1985) Production and characterization of $\mathrm{N}$-terminally and C-terminally directed monoclonal antibodies against pancreatic glucagon. Gastroenterology 89:571-580.

Hitchcock P, Ochocinska M, Sieh A, Otteson D (2004) Persistent and injury-induced neurogenesis in the vertebrate retina. Prog Retin Eye Res 23:183-194.

Irwin DM, Wong J (1995) Trout and chicken proglucagon: alternative splicing generates mRNA transcripts encoding glucagon-like peptide 2. Mol Endocrinol 9:267-277.

Karten HJ, Brecha N (1983) Localization of neuroactive substances in the vertebrate retina: evidence for lamination in the inner plexiform layer. Vision Res 23:1197-1205.

Kiyama H, Katayama-Kumoi Y, Kimmel J, Steinbusch H, Powell JF, Smith AD, Tohyama M (1985) Three dimensional analysis of retinal neuropeptides and amine in the chick. Brain Res Bull 15:155-165.

Kuwayama Y, Ishimoto I, Fukuda M, Shimiza Y, Shiosaka S, Inagaki S, Senba E, Sakanaka M, Takagi H, Takatsuki K, Hara Y, Kawai Y, Tohyama M (1982) Overall distribution of glucagon-like immunoreactivity in the chicken retina: an immunohistochemical study with flat-mounts. Invest Ophthalmol Vis Sci 22:681-686.

Moshiri A, McGuire CR, Reh TA (2005) Sonic hedgehog regulates proliferation of the retinal ciliary marginal zone in posthatch chicks. Dev Dyn 233:66-75
Nicot A, Lelievre V, Tam J, Waschek JA, DiCicco-Bloom E (2002) Pituitary adenylate cyclase-activating polypeptide and sonic hedgehog interact to control cerebellar granule precursor cell proliferation. J Neurosci 22:9244-9254

Ramon y Cajal S (1972) The structure of the retina, Chap VI (Thorpe SA, Glickstein M, eds), pp 76-92. Springfield, IL: Charles C. Thomas.

Raymond PA, Hitchcock PF (1997) Retinal regeneration: common principles but a diversity of mechanisms. Adv Neurol 72:171-184.

Raymond PA, Hitchcock PF (2000) How the neural retina regenerates. Results Probl Cell Differ 31:197-218.

Reh TA, Fischer AJ (2001) Stem cells in the vertebrate retina. Brain Behav Evol 58:296-305.

Tornqvist K, Ehinger B (1983) Glucagon immunoreactive neurons in the retina of different species. Graefes Arch Clin Exp Ophthalmol 220:1-5.

Tornqvist K, Loren I, Hakanson R, Sundler F (1981) Peptide-containing neurons in the chicken retina. Exp Eye Res 33:55-64.

Tropepe V, Coles BL, Chiasson BJ, Horsford DJ, Elia AJ, McInnes RR, van der Kooy D (2000) Retinal stem cells in the adult mammalian eye. Science 287:2032-2036.

Uchiyama H, Ito H (1993) Target cells for the isthmo-optic fibers in the retina of the Japanese quail. Neurosci Lett 154:35-38.

Uchiyama H, Ito H, Tauchi M (1995) Retinal neurones specific for centrifugal modulation of vision. NeuroReport 6:889-892.

Uchiyama H, Aoki K, Yonezawa S, Arimura F, Ohno H (2004) Retinal target cells of the centrifugal projection from the isthmo-optic nucleus. J Comp Neurol 476:146-153.

Velazquez E, Ruiz-Albusac JM, Blazquez E (2003) Glucagon-like peptide-2 stimulates the proliferation of cultured rat astrocytes. Eur J Biochem 270:3001-3009.

Vessy KA, Rushforth DA, Stell WK (2005a) Glucagon- and secretin-related peptide differentially alter ocular growth and the development of formdeprivation myopia in chicks. Invest Ophthalmol Vis Sci, in press.

Vessy KA, Lencses KA, Rushforth DA, Hurby VJ, Stell WK (2005b) Glucagon receptor agonists and antagonists affect the growth of the chick eye: a role for glucagonergic regulation of emmetropization? Invest Ophthalmol Vis Sci, in press.

Waschek JA, Dicicco-Bloom EM, Lelievre V, Zhou X, Hu Z (2000) PACAP action in nervous system development, regeneration, and neuroblastoma cell proliferation. Ann NY Acad Sci 921:129-136.

Wassle H, Riemann HJ (1978) The mosaic of nerve cells in the mammalian retina. Proc R Soc Lond B Biol Sci 200:441-461.

Wetzel RK, Eldred WD (1997) Specialized neuropeptide Y- and glucagonlike immunoreactive amacrine cells in the peripheral retina of the turtle. Vis Neurosci 14:867-877. 